Article

\title{
Association between Optic Neuritis and Inflammatory Bowel Disease: A Population-Based Study
}

\author{
Yun-Hsiu Hsieh ${ }^{1}$, Chi-Hsiang Chung ${ }^{2,3,4}{ }^{10}$, Chien-An Sun ${ }^{5,6}$, Po-Huang Chen ${ }^{7} \oplus$, Yi-Hao Chen ${ }^{1}$, \\ Chang-Min Liang ${ }^{1}$, Jiann-Torng Chen ${ }^{1}$, Wu-Chien Chien ${ }^{2,3,4,8, * \mathbb{O}}$ and Ching-Long Chen ${ }^{1, *}$ \\ 1 Department of Ophthalmology, Tri-Service General Hospital, National Defense Medical Center, \\ Taipei City 11490, Taiwan; vv7788442200@gmail.com (Y.-H.H.); doc30879@ndmctsgh.edu.tw (Y.-H.C.); \\ doc30875@yahoo.com.tw (C.-M.L.); jt66chen@gmail.com (J.-T.C.) \\ 2 School of Public Health, National Defense Medical Center, Taipei City 11490, Taiwan; g694810042@gmail.com \\ 3 Department of Medical Research, Tri-Service General Hospital, National Defense Medical Center, \\ Taipei City 11490, Taiwan \\ 4 Taiwanese Injury Prevention and Safety Promotion Association, Taipei City 11490, Taiwan \\ 5 Department of Public Health, College of Medicine, Fu-Jen Catholic University, \\ New Taipei City 242062, Taiwan; 040866@mail.fju.edu.tw \\ 6 Big Data Research Center, College of Medicine, Fu-Jen Catholic University, New Taipei City 242062, Taiwan \\ 7 Department of Internal Medicine, Tri-Service General Hospital, National Defense Medical Center, \\ Taipei City 11490, Taiwan; chenpohuang@hotmail.com \\ 8 Graduate Institute of Life Sciences, National Defense Medical Center, Taipei City 11490, Taiwan \\ * Correspondence: chienwu@ndmctsgh.edu.tw (W.-C.C.); doc30881@mail.ndmctsgh.edu.tw (C.-L.C.); \\ Tel.: +886-2-87923311 (ext. 19189) (W.-C.C.); +886-953-665-793 (C.-L.C.); Fax: +886-2-87923311 (W.-C.C.); \\ +886-953-665-793 (C.-L.C.)
}

check for

updates

Citation: Hsieh, Y.-H.; Chung, C.-H.; Sun, C.-A.; Chen, P.-H.; Chen, Y.-H.; Liang, C.-M.; Chen, J.-T.; Chien, W.-C.; Chen, C.-L. Association between Optic Neuritis and Inflammatory Bowel Disease: A Population-Based Study. J. Clin. Med. 2021, 10, 688. https://doi.org/10.3390/jcm10040688

Academic Editor: Marilena Durazzo

Received: 13 January 2021

Accepted: 7 February 2021

Published: 10 February 2021

Publisher's Note: MDPI stays neutral with regard to jurisdictional claims in published maps and institutional affiliations.

Copyright: (c) 2021 by the authors. Licensee MDPI, Basel, Switzerland. This article is an open access article distributed under the terms and conditions of the Creative Commons Attribution (CC BY) license (https:// creativecommons.org/licenses/by/ $4.0 /)$.
Abstract: Extraintestinal manifestations are common in patients with inflammatory bowel disease (IBD), and optic neuritis (ON) is a rare but severe one. This study aimed to evaluate possible factors associated with ON in patients with IBD. Adult patients with IBD who were not with concomitant ON on the index date identified from the Taiwan National Health Insurance Research Database (NHIRD) from the years 2000 to 2013 were included. A four-fold matched group was selected using age, sex and year of index date for comparison. All the patients were followed up until the development of $\mathrm{ON}$ or the end of the study period. Data of included patients were extracted and analyzed statistically. The mean follow-up time for all patients was $7.13 \pm 5.21$ years. At the study period conclusion, eight $(0.18 \%)$ and five $(0.003 \%)$ patients with and without IBD, respectively, had developed ON ( $p=0.001)$. Adjusted HRs showed that patients with IBD aged between 30 and 39 years, with comorbidities including neuromyelitis optica (NMO), acute disseminated encephalomyelitis (ADEM), systemic lupus erythematosus (SLE) and with a higher Charlson Comorbidity Index, had a significantly higher risk of developing ON (all $p<0.005$ ). Among the eight IBD patients who developed ON, only one patient was diagnosed with Crohn's disease, the male gender was slightly dominant, and two (25\%) patients received antitumor necrosis factor $\alpha$ (anti-TNF $\alpha$ ) treatment for IBD. Patients with IBD have a higher risk of developing ON compared to patients without IBD. ON occurs more frequently in IBD patients aged between 30 and 39 years, with comorbidities including NMO, ADEM and SLE. Other factors besides anti-TNF $\alpha$ treatment for IBD are more likely associated with the development of $\mathrm{ON}$.

Keywords: Crohn's disease; extraintestinal manifestation; inflammatory bowel disease; optic neuritis; ocular manifestation; ulcerative colitis

\section{Introduction}

Inflammatory bowel disease (IBD) comprises two main distinctive diseases, ulcerative colitis (UC) and Crohn's disease (CD), and is a chronic, idiopathic inflammatory condition occurring in the gastrointestinal (GI) tract [1]. IBD primarily affects people around 
15-35 years old, regardless of sex, and may persist nearly throughout life [2]. UC usually affects the colon in an uninterrupted pattern, whereas $C D$ may affect any region of the intestine [3]. The major complaints of patients with IBD are colonic symptoms due to colonic tissue damage caused by gastrointestinal inflammation; however, $6 \%$ to $47 \%$ of IBD patients are reported to present extraintestinal manifestation (EIM), depending on the definitions applied across the studies [4-6], which means experiencing symptoms outside the GI tract such as in joints, mouth, skin, liver and eyes [7,8].

Optic neuritis $(\mathrm{ON})$ is a demyelinating inflammation or degeneration of the optic nerve, including the optic nerve head, optic nerve sheath and optic nerve itself, leading to complete or partial visual impairment due to the swelling and destruction of the myelin sheath covering the optic nerve $[9,10]$. The incidence of ocular IBD EIM ranged from $1.0 \%$ to $43 \%$ in previous studies [11-13], and ON may present in up to $4 \%$ of these IBD patients $[11,14]$. Although rare, due to the severe impact on the quality of life, it is important to understand the features of $\mathrm{ON}$ within the disease course of IBD, including the pathologic mechanisms and risk factors, to avoid irreversible loss of vision.

The etiology of ON in IBD patients remains a matter of controversy. ON can be seen as an isolated disease, a sign of autoimmune disease like IBD, a manifestation of neurologic disease or an early sign of demyelination disease, such as multiple sclerosis (MS) [15-18]. In particular, the link with IBD has been mentioned for decades. For example, a retrospective cohort study revealed that MS and ON occur more commonly among patients with IBD than among non-IBD patients [19], making clarifying the etiology of ON in patients with IBD more difficult. In addition, secondary antitumor necrosis factor $\alpha$ (anti-TNF $\alpha$ )-induced or anti-TNF $\alpha$-associated ON has been reported in association with the wider use of anti-TNF $\alpha$ therapy for a variety of autoimmune diseases, including IBD and MS [20-24]. All of the above-mentioned factors expand the complexity and possible underlying mechanisms related to the occurrence of ON in patients with IBD.

This study aimed to evaluate the possible factors associated with the incidence of ON in patients with IBD. Our ultimate goal was to increase awareness of ON in patients with IBD and provide useful information for all the physicians in the multidisciplinary care team treating this rare condition.

\section{Methods}

\subsection{Data Source}

Medical data were extracted from the deidentified National Health Insurance Research Database (NHIRD) from 2000 to 2013. More than 25 million people are eligible for participation in the National Health Insurance (NHI) program, including up to $99.91 \%$ of the residents of Taiwan and non-Taiwanese residents living in Taiwan currently. The NHIRD contains registration files and original claims data for reimbursement. For the present study, age, sex, index year, clinical visits, medications and diagnostic codes were extracted and analyzed. The International Classification of Disease, Ninth Revision, Clinical Modification (ICD-9-CM) was used to define the diagnostic codes. The ICD-9-CM codes used in the present study are listed in Table S1. Anti-TNF $\alpha$ use was defined as at least 3 times the prescription records of adalimumab (Humira; AbbVie Inc., North Chicago, IL, USA, drug code: KC01039271) and infliximab (Remicade; Janssen Biotech, Inc., Malvern, PA, USA; drug code: KC00980255, Remsima; Celltrion Inc., Incheon, Korea, drug code: KC01035255) after the diagnosis of IBD and before the diagnosis of $\mathrm{ON}$, given that the $\mathrm{NHI}$ approved the use of these two drugs only for the treatment of IBD during the study period.

\subsection{Ethical Considerations}

The study protocol was reviewed and approved by the Institutional Review Board of Tri-Service General Hospital (TSGH IRB No. A202005062). Because the data from NHI were deidentified, signed informed consent of included patients was waived. 


\subsection{Patient Selection}

All included patients were at least 20 years old at diagnosis of IBD, had records of outpatient or inpatient visits with a diagnosis of IBD at least 3 times during the study period and not limited to the main diagnosis. Patients with tuberculosis, Lyme disease, syphilis and Herpes zoster ophthalmicus from before 1 year to after 1 year of the index date were excluded. In addition, patients who were documented as having IBD before 1 January 2000 or had incomplete medical records, defined as the insurance status being incomplete or the given codes unrelated or incorrect, were also excluded. A group of patients who were four-fold matched with the IBD group was selected as the control, using age (each 5-year span), sex and year of the index date for matching. Patients were followed until the incidence of $\mathrm{ON}$ in the records of outpatient or inpatient visits, or until the end of the study period (31 December 2013). Figure 1 shows a flowchart of the patient selection.
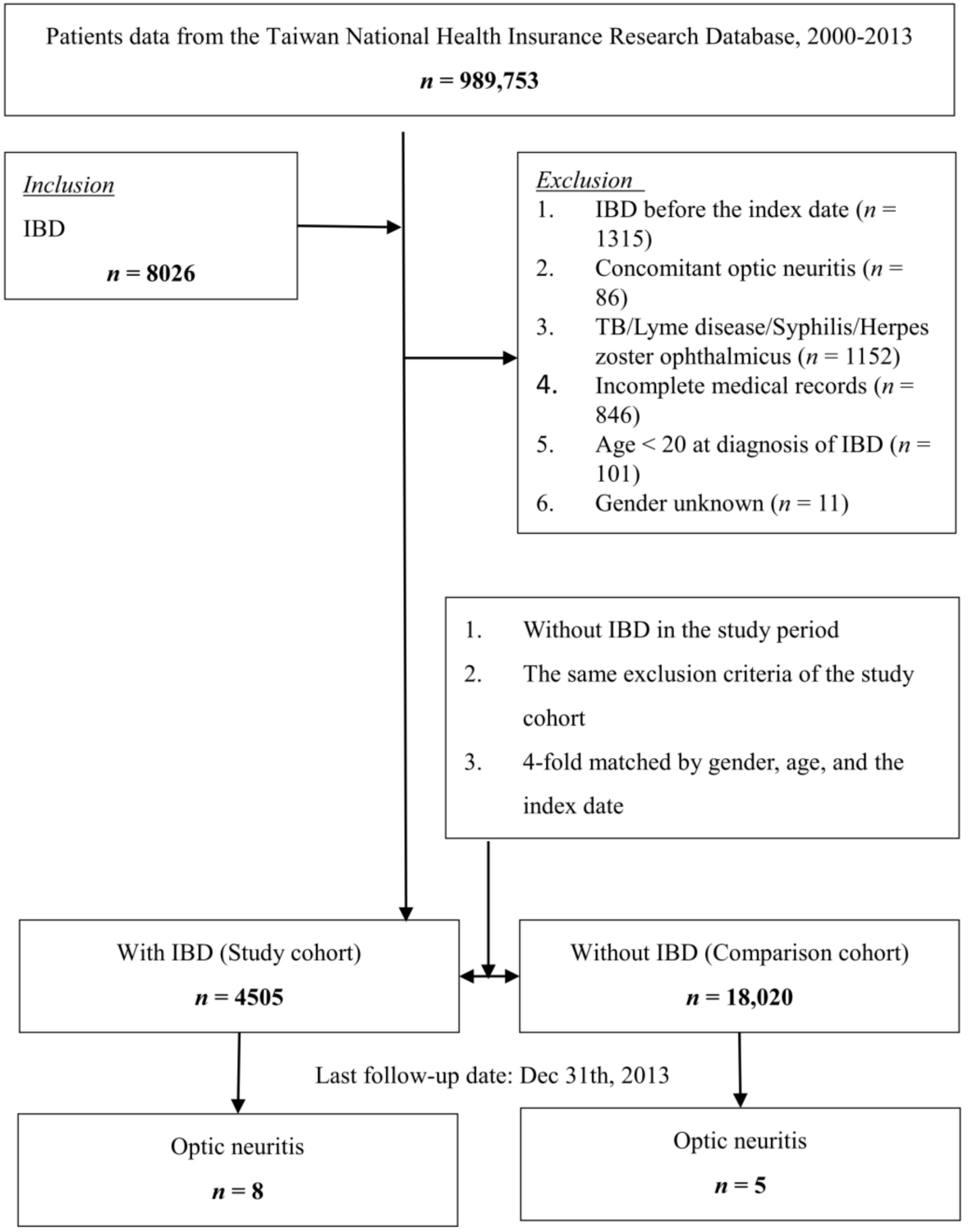

Figure 1. Flowchart of this study.

\subsection{Statistical Analysis}

Pearson's chi-square test and Fisher's exact test were used to evaluate the differences in categorical variables, including sex and age group. After adjusting for confounding variables, univariate and multivariate Cox regression analyses were employed to evaluate 
the adjusted hazard ratios for the influence (odds) of analyzed variables on developing ON. Kaplan-Meier analysis was performed to estimate the development of ON in these two cohorts. All statistical analyses were performed using SPSS software (version 22.0; SPSS Inc., Chicago, IL, USA). Statistical significance was defined as $p<0.05$.

\section{Results}

Table 1 shows the demographic and clinical characteristics of the enrolled patients at baseline. A total of 22,525 patients were enrolled, including 4505 patients with IBD and 18,020 age-, sex- and index-year-matched patients. The mean ages of patients with and without IBD were $55.36 \pm 17.45$ and $55.13 \pm 17.53$ years, respectively. The mean follow-up time was $7.13 \pm 5.21$ (range: 0.01 to 13.99 ) years for all patients.

Table 1. Patients' demographic and clinical characteristics at baseline.

\begin{tabular}{|c|c|c|c|c|c|}
\hline \multirow[b]{2}{*}{ Variables } & \multicolumn{2}{|c|}{ With IBD } & \multicolumn{2}{|c|}{ Without IBD } & \multirow{2}{*}{$p$} \\
\hline & $n$ & $\%$ & $n$ & $\%$ & \\
\hline Total & 4505 & 20.00 & 18,020 & 80.00 & \\
\hline Gender & & & & & 0.999 \\
\hline Male & 2427 & 53.87 & 9708 & 53.87 & \\
\hline Female & 2078 & 46.13 & 8312 & 46.13 & \\
\hline Age (years) ${ }^{a}$ & \multicolumn{2}{|c|}{$55.36 \pm 17.45$} & \multicolumn{2}{|c|}{$55.13 \pm 17.53$} & 0.432 \\
\hline Age groups (years) & & & & & 0.999 \\
\hline $20-29$ & 448 & 9.94 & 1792 & 9.94 & \\
\hline $30-39$ & 655 & 14.54 & 2620 & 14.54 & \\
\hline $40-49$ & 675 & 14.98 & 2700 & 14.98 & \\
\hline $50-59$ & 637 & 14.14 & 2548 & 14.14 & \\
\hline$\geq 60$ & 2090 & 46.39 & 8360 & 46.39 & \\
\hline$\overline{\text { Multiple sclerosis }}$ & & & & & $<0.001^{*}$ \\
\hline Without & 4379 & 97.20 & 17,918 & 99.43 & \\
\hline With & 126 & 2.80 & 102 & 0.57 & \\
\hline Neuromyelitis optica & & & & & $<0.001$ * \\
\hline Without & 4407 & 97.82 & 17,978 & 99.77 & \\
\hline With & 98 & 2.18 & 42 & 0.23 & \\
\hline Acute disseminated encephalomyelitis & & & & & $<0.001$ * \\
\hline Without & 4392 & 97.49 & 17,953 & 99.63 & \\
\hline With & 113 & 2.51 & 67 & 0.37 & \\
\hline Sarcoidosis & & & & & $<0.001$ * \\
\hline Without & 4427 & 98.27 & 17,988 & 99.82 & \\
\hline With & 78 & 1.73 & 32 & 0.18 & \\
\hline SLE & & & & & $<0.001 *$ \\
\hline Without & 4230 & 93.90 & 17,789 & 98.72 & \\
\hline With & 275 & 6.10 & 231 & 1.28 & \\
\hline Behçet syndrome & & & & & $<0.001 *$ \\
\hline Without & 4472 & 99.27 & 18,008 & 99.93 & \\
\hline With & 33 & 0.73 & 12 & 0.07 & \\
\hline Antiphospholipid antibody syndrome & & & & & $<0.001^{*}$ \\
\hline Without & 4486 & 99.58 & 18,017 & 99.98 & \\
\hline With & 19 & 0.42 & 3 & 0.02 & \\
\hline Granulomatosis with polyangiitis & & & & & $<0.001$ * \\
\hline Without & 4477 & 99.38 & 18,013 & 99.96 & \\
\hline With & 28 & 0.62 & 7 & 0.04 & \\
\hline Sicca syndrome & & & & & $<0.001 *$ \\
\hline Without & 4307 & 95.60 & 17,942 & 99.57 & \\
\hline With & 198 & 4.40 & 78 & 0.43 & \\
\hline CCI ${ }^{a}$ & & & & & $<0.001$ * \\
\hline Anti-TNF use & & & & & \\
\hline Without & 3518 & 78.09 & NA & NA & \\
\hline With & 987 & 21.91 & NA & NA & \\
\hline
\end{tabular}

${ }^{*}$ indicates a significant difference between the 2 groups with/without IBD, $p<0.05$. ${ }^{a}$ presented as mean \pm SD. CCI: Charlson comorbidity index, IBD: inflammatory bowel disease, NA: not available, NTD: new Taiwan dollar, SLE: systemic lupus erythematosus, TNF: tumor necrosis factor. 
For comorbidities, higher proportions of MS, neuromyelitis optica (NMO), acute disseminated encephalomyelitis (ADEM), sarcoidosis, systemic lupus erythematosus (SLE), Behçet syndrome, antiphospholipid antibody syndrome, granulomatosis with polyangiitis (GPA) or Sicca syndrome were found in patients with IBD (all $p<0.001$ ), compared to those without IBD. Patients with IBD had higher Charlson Comorbidity Index (CCI) values than patients without IBD $(p<0.001)$. In patients with IBD, $987(21.91 \%)$ were treated with anti-TNF $\alpha$ drugs.

At the study conclusion, eight $(0.18 \%)$ and five $(0.003 \%)$ patients had developed ON in the patients with and without IBD groups, respectively, with a significant difference in prevalence shown between the two groups $(p=0.001)$. The mean time for ON to develop for patients with IBD was $5.43 \pm 4.23$ years and $9.24 \pm 3.98$ years for patients without IBD. Results of the Kaplan-Meier analysis for the cumulative risk of developing ON in patients with IBD and patients without IBD are shown in Figure 2. Patients with IBD had significantly higher odds of developing ON compared to patients without IBD, with logrank test $p=0.003$. Differences in risk between the two groups were significant in each year of the total 14 years of follow-up (all $p<0.016$ ). Adjusted HRs showed that patients with IBD aged between 30 and 39 years, with comorbidities including NMO, ADEM and SLE, and with a higher CCI had a significantly higher risk of developing optic neuritis (Table 2).

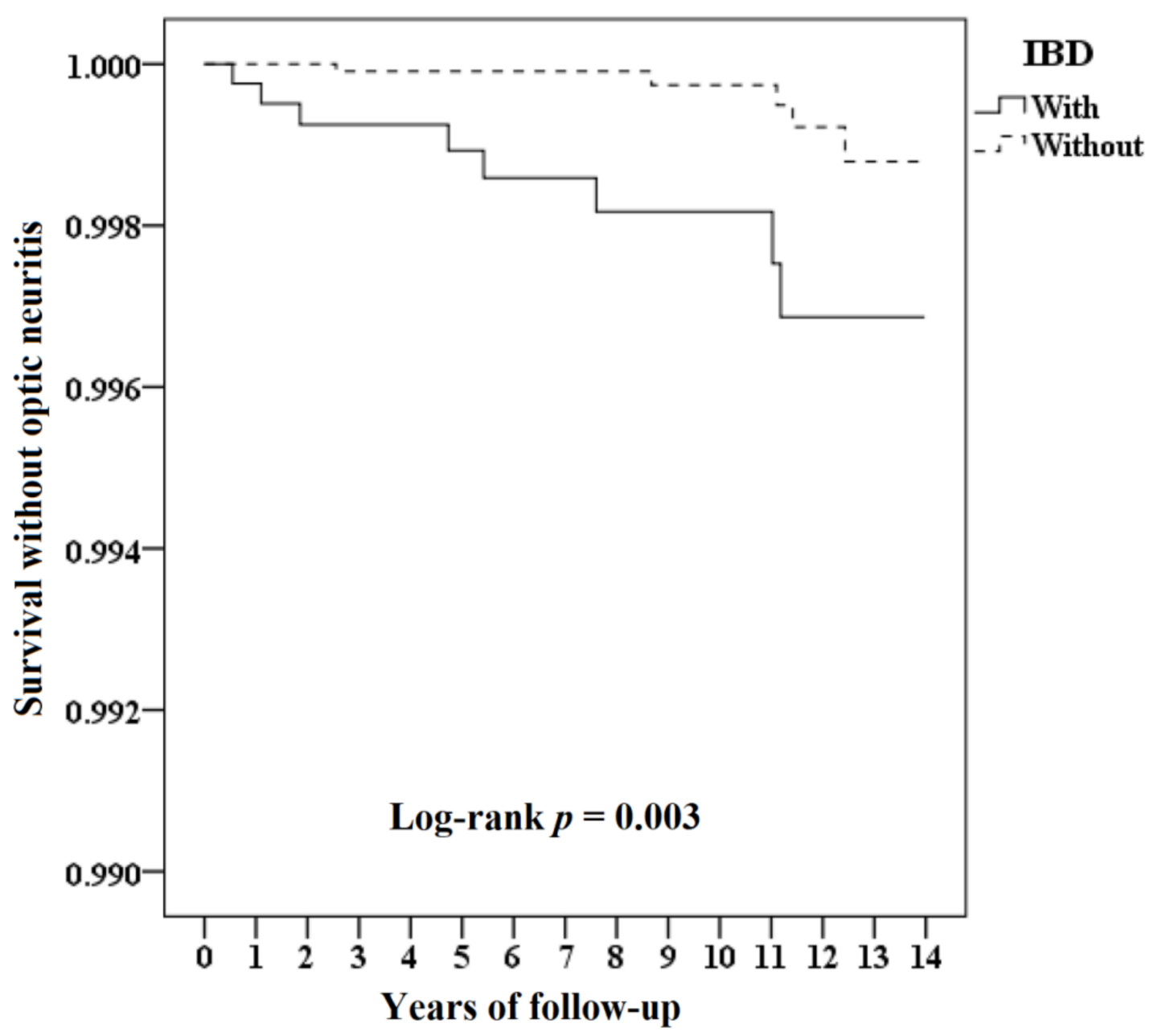

Figure 2. Kaplan-Meier curve for optic neuritis, stratified by IBD with the log-rank test. 
Table 2. Risk analysis for optic neuritis.

\begin{tabular}{|c|c|c|c|c|}
\hline Variables & Crude HR (95\% CI) & $p$ & Adjusted HR (95\% CI) & $p$ \\
\hline \multicolumn{5}{|l|}{ IBD } \\
\hline Without & Reference & & Reference & \\
\hline With & $4.020(1.366-10.257)$ & $0.003 *$ & $4.211(1.352-12.978)$ & 0.001 * \\
\hline \multicolumn{5}{|l|}{ Gender } \\
\hline Male & $1.168(0.482-3.279)$ & 0.812 & $1.053(0.351-3.240)$ & 0.873 \\
\hline Female & Reference & & Reference & \\
\hline \multicolumn{5}{|l|}{ Age groups (years) } \\
\hline $20-29$ & 0 & 0.990 & 0 & 0.995 \\
\hline $30-39$ & 6.725 (1.573-28.897) & $0.008 *$ & $6.682(1.511-28.035)$ & 0.009 * \\
\hline $40-49$ & $1.026(0.126-7.893)$ & 0.837 & $1.010(0.108-7.772)$ & 0.913 \\
\hline $50-59$ & $3.211(0.894-12.010)$ & 0.075 & $3.145(0.842-10.986)$ & 0.086 \\
\hline$\geq 60$ & Reference & & Reference & \\
\hline \multicolumn{5}{|l|}{ Multiple sclerosis } \\
\hline Without & Reference & & Reference & \\
\hline With & $1.765(0.702-3.010)$ & 0.245 & $1.628(0.527-2.913)$ & 0.311 \\
\hline \multicolumn{5}{|l|}{ Neuromyelitis optica } \\
\hline Without & Reference & & Reference & \\
\hline With & $3.010(1.898-5.896)$ & $<0.001 *$ & $2.843(1.625-5.113)$ & $<0.001$ * \\
\hline \multicolumn{5}{|c|}{ Acute disseminated encephalomyelitis } \\
\hline Without & Reference & & Reference & \\
\hline With & $3.346(2.113-6.124)$ & $<0.001 *$ & $3.084(1.989-6.001)$ & $<0.001$ * \\
\hline \multicolumn{5}{|l|}{ Sarcoidosis } \\
\hline Without & Reference & & Reference & \\
\hline With & $1.845(0.896-3.182)$ & 0.137 & $1.692(0.533-2.873)$ & 0.296 \\
\hline \multicolumn{5}{|l|}{ SLE } \\
\hline Without & Reference & & Reference & \\
\hline With & $2.010(1.256-4.335)$ & $<0.001 *$ & $1.997(1.154-4.237)$ & $<0.001 *$ \\
\hline \multicolumn{5}{|l|}{ Behçet syndrome } \\
\hline Without & Reference & & Reference & \\
\hline With & 0 & 0.985 & 0 & 0.990 \\
\hline \multicolumn{5}{|c|}{ Antiphospholipid antibody syndrome } \\
\hline Without & Reference & & Reference & \\
\hline With & 0 & 0.972 & 0 & 0.986 \\
\hline \multicolumn{5}{|c|}{ Granulomatosis with polyangiitis } \\
\hline Without & Reference & & Reference & \\
\hline With & 0 & 0.989 & 0 & 0.992 \\
\hline \multicolumn{5}{|l|}{ Sicca syndrome } \\
\hline Without & Reference & & Reference & \\
\hline With & $1.765(0.720-2.765)$ & 0.512 & $1.507(0.562-2.631)$ & 0.651 \\
\hline CCI & $1.334(1.112-1.509)$ & $<0.001 *$ & $1.218(1.097-1.486)$ & $<0.001$ * \\
\hline \multicolumn{5}{|l|}{ Anti-TNF $\alpha$ use } \\
\hline Without & Reference & & Reference & \\
\hline With & $0.674(0.195-1.243)$ & 0.712 & $0.732(0.211-1.209)$ & 0.564 \\
\hline
\end{tabular}

Adjusted HR means adjusted for variables listed in the table. * indicates a significant difference between the 2 groups with/without IBD, $p<0.05$. CCI: Charlson Comorbidity Index, CI: confidence interval, HR: hazard ratio, IBD: inflammatory bowel disease, NA: not available, SLE: systemic lupus erythematosus, TNF: tumor necrosis factor.

The results of subgroup analysis comparing patients with and without IBD are shown in Table 3. The overall incidence of ON was 20.25 per 100,000 person-years in patients with IBD and 4.27 per 100,000 person-years in patients without IBD. Patients with IBD had an increased risk of developing ON regardless of sex. The adjusted HR was 4.503 in males and 3.831 in females $(p<0.001)$. IBD patients in the 30 to 39 and 50 to 59 years age groups were independently associated with a significantly increased risk of developing ON than patients without IBD, with an adjusted HR of 5.096 in the 30-39 years age group and 3.642 in the $50-59$ years age group $(p<0.001)$. For comorbidities, IBD patients with MS, NMO, ADEM and SLE had significantly higher risks for developing ON, with adjusted HRs of 3.759, 3.202, 3.306 and 3.896, respectively (all $p \leq 0.005$ ). IBD patients without 
Behçet syndrome, antiphospholipid antibody syndrome or GPA also had a significantly higher risk of developing ON (adjusted HRs all 4.211, $p=0.001$ ).

Table 3. Risk analysis for optic neuritis stratified by demographic and clinical characteristics between patients with/without IBD.

\begin{tabular}{|c|c|c|c|c|c|c|c|}
\hline \multirow[b]{2}{*}{ Stratified } & \multicolumn{2}{|c|}{ With IBD } & \multicolumn{2}{|c|}{ Without IBD } & \multirow[t]{2}{*}{ Ratio } & \multicolumn{2}{|c|}{ With vs. Without (Reference) } \\
\hline & \multicolumn{2}{|c|}{ EventsRate (per $10^{5}$ PYs) } & \multicolumn{2}{|c|}{ EventsRate (per $10^{5}$ PYs) } & & \multirow{3}{*}{$\begin{array}{c}\text { Adjusted HR (95\% CI) } \\
4.211(1.352-12.978)\end{array}$} & \multirow{3}{*}{$\frac{p}{0.001 *}$} \\
\hline Total & 8 & 20.25 & 5 & 4.27 & 4.737 & & \\
\hline Gender & & & & & & & \\
\hline Male & 5 & 24.44 & 3 & 4.82 & 5.069 & $4.503(1.446-13.875)$ & $<0.001 *$ \\
\hline Female & 3 & 15.74 & 2 & 3.65 & 4.311 & $3.831(1.229-11.819)$ & $<0.001 *$ \\
\hline \multicolumn{8}{|c|}{ Age groups (years) } \\
\hline $20-29$ & 0 & 0 & 0 & 0.00 & - & - & - \\
\hline $30-39$ & 2 & 73.90 & 1 & 12.90 & 5.729 & $5.096(1.627-15.663)$ & $<0.001 *$ \\
\hline $40-49$ & 1 & 17.60 & 0 & 0 & $\infty$ & $\infty$ & 0.988 \\
\hline $50-59$ & 3 & 49.03 & 2 & 11.96 & 4.099 & $3.642(1.189-11.243)$ & $<0.001 *$ \\
\hline$\geq 60$ & 2 & 8.09 & 2 & 2.57 & 3.145 & $2.789(0.842-8.512)$ & 0.099 \\
\hline \multicolumn{8}{|c|}{ Multiple sclerosis } \\
\hline Without & 3 & 7.79 & 4 & 3.44 & 2.261 & $2.008(0.643-6.185)$ & 0.289 \\
\hline With & 5 & 510.71 & 1 & 120.53 & 4.237 & 3.759 (1.201-11.522) & $<0.001 *$ \\
\hline \multicolumn{8}{|l|}{$\begin{array}{l}\text { Neuromyelitis } \\
\text { optica }\end{array}$} \\
\hline Without & 0 & 0 & 4 & 3.43 & 0 & 0 & 0.897 \\
\hline With & 8 & 1050.61 & 1 & 292.72 & 3.589 & 3.202 (1.067-9.976) & $<0.001^{*}$ \\
\hline \multicolumn{8}{|c|}{$\begin{array}{l}\text { Acute } \\
\text { disseminated } \\
\text { encephalomyelitis }\end{array}$} \\
\hline Without & 2 & 5.18 & 4 & 3.44 & 1.507 & $1.333(0.415-4.086)$ & 0.534 \\
\hline With & 6 & 683.36 & 1 & 183.49 & 3.724 & $3.306(1.048-9.975)$ & $0.005 *$ \\
\hline \multicolumn{8}{|l|}{ Sarcoidosis } \\
\hline Without & 4 & 10.28 & 5 & 4.28 & 2.400 & $2.146(0.698-6.672)$ & 0.349 \\
\hline With & 4 & 660.00 & 0 & 0.00 & $\infty$ & $\infty$ & 0.880 \\
\hline \multicolumn{8}{|l|}{ SLE } \\
\hline Without & 3 & 8.03 & 4 & 3.48 & 2.310 & $2.042(0.617-6.285)$ & 0.297 \\
\hline With & 5 & 234.00 & 1 & 53.22 & 4.397 & $3.896(1.230-11.983)$ & $<0.001 *$ \\
\hline \multicolumn{8}{|c|}{ Behçet syndrome } \\
\hline Without & 8 & 20.38 & 5 & 4.28 & 4.764 & $4.211(1.352-12.978)$ & $0.001 *$ \\
\hline With & 0 & 0.00 & 0 & 0.00 & - & - & - \\
\hline \multicolumn{8}{|c|}{$\begin{array}{l}\text { Antiphospholipid } \\
\text { antibody } \\
\text { syndrome }\end{array}$} \\
\hline Without & 8 & 20.32 & 5 & 4.28 & 4.754 & $4.211(1.352-12.978)$ & $0.001 *$ \\
\hline With & 0 & 0.00 & 0 & 0.00 & - & - & - \\
\hline \multicolumn{8}{|c|}{$\begin{array}{l}\text { Granulomatosis } \\
\text { with polyangiitis }\end{array}$} \\
\hline Without & 8 & 20.36 & 5 & 4.28 & 4.761 & $4.211(1.352-12.978)$ & $0.001 *$ \\
\hline With & 0 & 0.00 & 0 & 0 & - & - & - \\
\hline \multicolumn{8}{|l|}{ Sicca syndrome } \\
\hline Without & 4 & 10.53 & 5 & 4.30 & 2.451 & $2.165(0.684-6.686)$ & 0.275 \\
\hline With & 4 & 260.00 & 0 & 0 & $\infty$ & $\infty$ & 0.859 \\
\hline
\end{tabular}

Adjusted HR means adjusted for the variables listed in Table 3. * indicates a significant difference between the 2 groups with/without IBD, $p<$ 0.05. CCI: Charlson Comorbidity Index, CI: confidence interval, HR: hazard ratio, IBD: inflammatory bowel disease, NA: not available, PYs: person-years, SLE: systemic lupus erythematosus. $\infty$ indicates infinity.

Detailed information of the eight patients in the IBD group who developed ON is listed in Table 4. Only one patient was diagnosed with Crohn's disease, and the male gender was slightly dominant, with five males among the eight patients. Only two patients received anti-TNF $\alpha$ treatment for IBD. The time for ON to develop after diagnosis of IBD was diverse, ranging from within 1 year to 11.18 years. 
Table 4. Characteristics of patients with optic neuritis among the IBD cohort.

\begin{tabular}{|c|c|c|c|c|c|c|c|c|}
\hline Patient & 1 & 2 & 3 & 4 & 5 & 6 & 7 & 8 \\
\hline $\begin{array}{l}\text { Time to optic } \\
\text { neuritis (years) }\end{array}$ & 0.55 & 1.25 & 2.12 & 4.41 & 5.73 & 8.69 & 9.51 & 11.18 \\
\hline IBD type & $\begin{array}{l}\text { Ulcerative } \\
\text { colitis }\end{array}$ & $\begin{array}{l}\text { Ulcerative } \\
\text { colitis }\end{array}$ & $\begin{array}{l}\text { Crohn's } \\
\text { disease }\end{array}$ & $\begin{array}{l}\text { Ulcerative } \\
\text { colitis }\end{array}$ & $\begin{array}{l}\text { Ulcerative } \\
\text { colitis }\end{array}$ & $\begin{array}{l}\text { Ulcerative } \\
\text { colitis }\end{array}$ & $\begin{array}{l}\text { Ulcerative } \\
\text { colitis }\end{array}$ & $\begin{array}{l}\text { Ulcerative } \\
\text { colitis }\end{array}$ \\
\hline Sex & Male & Female & Male & Male & Female & Male & Male & Female \\
\hline Age (years) & 47.03 & 59.21 & 34.11 & 56.69 & 84.19 & 72.04 & 59.36 & 35.92 \\
\hline Anti-TNF $\alpha$ use & No & No & No & No & Yes & No & No & Yes \\
\hline Mortality & Survival & Survival & Survival & Survival & Mortality & Mortality & Survival & Survival \\
\hline
\end{tabular}

CI: confidence interval, HR: hazard ratio, IBD: inflammatory bowel disease, TNF: tumor necrosis factor.4. Discussion.

\section{Discussion}

In this population-based cohort study, 4505 patients with IBD were identified from a million-level database and followed for a mean follow-up of 7 years. Only eight $(0.18 \%)$ patients with IBD developed ON but still had a significantly higher rate than patients without IBD. The incidence of ON in patients with IBD was 20.25 per 100,000 personyears and over four-fold higher than that in patients without IBD. Concurrence of other autoimmune diseases was significantly more frequent in patients with IBD compared to patients without IBD. Within the eight patients in the IBD group who developed ON, two patients received anti-TNF $\alpha$ treatment for IBD, which may suggest that other factors besides the use of anti-TNF $\alpha$ agents are more likely associated with ON.

The prevalence and incidence of ophthalmic manifestations in patients with IBD vary across studies [25]. The reported prevalence of ophthalmic manifestations in IBD in surveys and medical chart review studies ranged from $2 \%$ to $5 \%$ [26-28] and was even lower ( $1 \%$ to $2 \%$ ) in a population-based study $[4,19]$. Our result of $0.18 \%$ was higher than that in a population-based study conducted in 2005, in which around $0.11 \%$ was reported [19]. We used the claims data based on the ICD-9-CM of this ocular finding coded by the ophthalmologists after evaluation. Felekis et al. [11] found that ophthalmic manifestations were significantly more prevalent after a thorough evaluation by the ophthalmologist is performed, which may be a possible reason. However, due to the small numbers (only 13 patients, 8 and 5 patients with and without IBD, respectively, who had developed $\mathrm{ON}$ in this large cohort), the significance revealed by the Kaplan-Meier analysis must be explained carefully to avoid overstating and misleading.

Adverse effects of anti-TNF $\alpha$ have been discussed intensively as the possible etiology of new-onset demyelination diseases in patients with IBD. For ON, several case reports have indicated that this may be due to the onset time being close to the start of the antiTNF $\alpha$ treatment, and the condition was reversed in some cases after discontinuing the use of anti-TNF $\alpha$ agent $[22-24,29,30]$. The issue remains inconclusive and unresolved. Gupta et al. performed a retrospective cohort study and a retrospective cross-sectional study using the data of the era before anti-TNF $\alpha$ treatment (1988 to 1997), and the results demonstrated that regardless of anti-TNF $\alpha$ use, patients with IBD were more likely to have a higher incidence of MS, demyelination and ON compared with a matched control. In a recent retrospective multicenter study of a large database and a comprehensive literature review, Alexandre et al. [30] identified 26 cases of optic neuritis from the literature and the European Crohn's and Colitis Organisation's Collaborative Network for Exceptionally Rare case reports (CONFER) database. Sixteen patients were under anti-TNF $\alpha$ treatment, and 10 patients were without anti-TNF- $\alpha$ treatment. The authors concluded that the causal association between anti-TNF $\alpha$ and the onset of ON was still uncertain. These results are consistent with our results, albeit probably not all ON occurring in patients with IBD are related to the use of anti-TNF $\alpha$ agents.

It is well known that in patients with IBD, comorbid IBD usually coexists with other autoimmune diseases. For example, a high association has been reported between IBD and MS [15-19]. ON can be seen as the first presenting sign of MS, and the cumulative 
probability of developing MS after onset of ON within 15 years is $50 \%$ [31]. ON also is one of the EIMs of IBD, indicating the possibility that ON may be caused by the underlying predisposition of IBD [32]. However, the results of the present study still cannot draw a clear relationship between MS, IBD, ON and other autoimmune and/or demyelinating diseases.

A major strength of this study is the use of a nationwide Taiwanese population sample. This design reduced selection bias and made the results applicable to the general population of Taiwan and accurate for the evaluation of a rare condition like ON. However, the results are limited by the uniform ethnic background. Two studies, both conducted in the United States, evaluated whether there is any difference between patients with IBD who live in the United States with different ethnic backgrounds. A cohort study conducted by Kocher et al. reported that Asians were more likely to have ocular manifestations compared to whites (3.4\% versus $0.7 \%, p=0.022$ ) [33]; however, a systematic review of 47 studies indicated that no major differences were seen in EIM among races and ethnic groups [34]. To the best of our knowledge, no data about the incidence of $\mathrm{ON}$ in different ethnic groups are reported, and the impact of genetic background needs to be explored in the future.

There are still some other limitations of the present study. The NHIRD database does not provide laboratory or clinical information such as MRI findings for the classification of disease severity, which might also play a role in developing ON [35]. For the same reason, the accuracy of diagnosis cannot be reconfirmed in this study. We did not extract all the medications used for IBD, which may miss some possible causes of ON. Furthermore, the impacts of other ocular manifestations, including episcleritis and scleritis in the incidence of $\mathrm{ON}$ in patients with IBD, were not analyzed since they are rare. Studies for further evaluation of the association should be conducted in the future.

In conclusion, patients with IBD have a higher risk of developing ON compared to patients without IBD. Because IBD has been known to be related to many neurological, immunological and ophthalmic conditions, a multidisciplinary care team may be necessary for diagnosis and to discuss appropriate programs of treatment and follow-up. Early and routine screening of visual function in patients with IBD may be important, especially in patients with a higher risk of ON.

Supplementary Materials: The following are available online at https://www.mdpi.com/2077-038 3/10/4/688/s1, Table S1: ICD-9-CM and definition used in this study.

Author Contributions: Conceptualization, C.-L.C., W.-C.C. and Y.-H.H.; methodology, Y.-H.H., P.-H.C., C.-H.C. and W.-C.C.; software, C.-H.C., C.-A.S. and W.-C.C.; validation, C.-L.C., W.-C.C. and Y.-H.H.; formal analysis, C.-H.C. and W.-C.C.; investigation, Y.-H.H.; resources, W.-C.C.; data curation, C.-H.C. and W.-C.C.; writing-original draft preparation, Y.-H.H.; writing-review and editing, Y.-H.C., C.-M.L., J.-T.C., C.-H.C., C.-A.S. and W.-C.C.; visualization, P.-H.C., Y.-H.C., C.-M.L., J.-T.C., supervision, Y.-H.C., C.-M.L., J.-T.C., C.-L.C., C.-A.S. and W.-C.C.; project administration, C.-L.C., C.-A.S. and W.-C.C.; funding acquisition, C.-L.C. and W.-C.C. All authors have read and agreed to the published version of the manuscript.

Funding: This study was supported by the Tri-Service General Hospital Research Foundation (TSGH-B-110012, TSGH-D-110112, TSGH-D-110109) and by the Ministry of National Defense (MNDMAB-110-084, MAB-E-110001). The sponsor has no role in study design, data collection and analysis, decision to publish, or preparation of the manuscript.

Institutional Review Board Statement: The study was conducted according to the guidelines of the Declaration of Helsinki, and approved by the Institutional Review Board of TSGH IRB No. A202005062, approved on 5 May 2020.

Informed Consent Statement: Patient consent was waived due to the National Health Insurance (NHI) dataset consists of de-identified secondary data used for research purposes, and the IRB gave a formal written waiver of the need for consent.

Data Availability Statement: Data is contained within the article and supplementary material.

Acknowledgments: This study was supported by the Tri-Service General Hospital Research Foundation (TSGH-B-110012), and the sponsor has no role in study design, data collection and analysis, 
decision to publish, or preparation of the manuscript. We also appreciate the Health and Welfare Data Science Center, Ministry of Health and Welfare (HWDC, MOHW), Taiwan, for providing the National Health Insurance Research Database (NHIRD).

Conflicts of Interest: No potential conflicts of interest relevant to this article were reported.

\section{References}

1. Baumgart, D.C.; Sandborn, W.J. Inflammatory bowel disease: Clinical aspects and established and evolving therapies. Lancet 2007, 369, 1641-1657. [CrossRef]

2. Seyedian, S.S.; Nokhostin, F.; Malamir, M.D. A review of the diagnosis, prevention, and treatment methods of inflammatory bowel disease. J. Med. Life 2019, 12, 113-122. [CrossRef]

3. Kornbluth, A.; Sachar, D.B. Ulcerative colitis practice guidelines in adults: American College of Gastroenterology, Practice Parameters Committee. Am. J. Gastroenterol. 2010, 105, 501-523. [CrossRef]

4. Bernstein, C.N.; Blanchard, J.F.; Rawsthorne, P.; Yu, N. The prevalence of extraintestinal diseases in inflammatory bowel disease: A population-based study. Am. J. Gastroenterol. 2001, 96, 1116-1122. [CrossRef] [PubMed]

5. Ricart, E.; Panaccione, R.; Loftus, E.V., Jr.; Tremaine, W.J.; Harmsen, W.S.; Zinsmeister, A.R.; Sandborn, W.J. Autoimmune disorders and extraintestinal manifestations in first-degree familial and sporadic inflammatory bowel disease: A case-control study. Inflamm. Bowel Dis. 2004, 10, 207-214. [CrossRef] [PubMed]

6. Danese, S.; Semeraro, S.; Papa, A.; Roberto, I.; Scaldaferri, F.; Fedeli, G.; Gasbarrini, G.; Gasbarrini, A. Extraintestinal manifestations in inflammatory bowel disease. World J. Gastroenterol. 2005, 11, 7227-7236. [CrossRef] [PubMed]

7. Peyrin-Biroulet, L.; Loftus, E.V., Jr.; Colombel, J.F.; Sandborn, W.J. Long-term complications, extraintestinal manifestations, and mortality in adult Crohn's disease in population-based cohorts. Inflamm. Bowel Dis. 2011, 17, 471-478. [CrossRef] [PubMed]

8. Vavricka, S.R.; Schoepfer, A.; Scharl, M.; Lakatos, P.L.; Navarini, A.; Rogler, G. Extraintestinal Manifestations of Inflammatory Bowel Disease. Inflamm. Bowel Dis. 2015, 21, 1982-1992. [CrossRef] [PubMed]

9. Balcer, L.J. Clinical practice. Optic neuritis. N. Engl. J. Med. 2006, 354, 1273-1280. [CrossRef]

10. Foroozan, R.; Buono, L.M.; Savino, P.J.; Sergott, R.C. Acute demyelinating optic neuritis. Curr. Opin. Ophthalmol. 2002, 13, 375-380. [CrossRef] [PubMed]

11. Felekis, T.; Katsanos, K.; Kitsanou, M.; Trakos, N.; Theopistos, V.; Christodoulou, D.; Asproudis, I.; Tsianos, E.V. Spectrum and frequency of ophthalmologic manifestations in patients with inflammatory bowel disease: A prospective single-center study. Inflamm. Bowel Dis. 2009, 15, 29-34. [CrossRef] [PubMed]

12. Isene, R.; Bernklev, T.; Høie, O.; Munkholm, P.; Tsianos, E.; Stockbrügger, R.; Odes, S.; Palm, Ø.; Småstuen, M.; Moum, B. Extraintestinal manifestations in Crohn's disease and ulcerative colitis: Results from a prospective, population-based European inception cohort. Scand. J. Gastroenterol. 2015, 50, 300-305. [CrossRef] [PubMed]

13. Troncoso, L.L.; Biancardi, A.L.; de Moraes, H.V., Jr.; Zaltman, C. Ophthalmic manifestations in patients with inflammatory bowel disease: A review. World J. Gastroenterol. 2017, 23, 5836-5848. [CrossRef] [PubMed]

14. Ghanchi, F.D.; Rembacken, B.J. Inflammatory bowel disease and the eye. Surv. Ophthalmol. 2003, 48, 663-676. [CrossRef]

15. Sadovnick, A.D.; Paty, D.W.; Yannakoulias, G. Concurrence of multiple sclerosis and inflammatory bowel disease. N. Engl. J. Med. 1989, 321, 762-763.

16. Minuk, G.Y.; Lewkonia, R.M. Possible familial association of multiple sclerosis and inflammatory bowel disease. N. Engl. J. Med. 1986, 314, 586. [CrossRef] [PubMed]

17. Kimura, K.; Hunter, S.F.; Thollander, M.S.; Loftus, E.V., Jr.; Melton, L.J., III; O’Brien, P.C.; Rodriguez, M.; Phillips, S.F. Concurrence of inflammatory bowel disease and multiple sclerosis. Mayo Clin. Proc. 2000, 75, 802-806. [CrossRef]

18. Rang, E.H.; Brooke, B.N.; Hermon-Taylor, J. Association of ulcerative colitis with multiple sclerosis. Lancet 1982, 2, 555. [CrossRef]

19. Gupta, G.; Gelfand, J.M.; Lewis, J.D. Increased risk for demyelinating diseases in patients with inflammatory bowel disease. Gastroenterology 2005, 129, 819-826. [CrossRef] [PubMed]

20. Bosch, X.; Saiz, A.; Ramos-Casals, M. Monoclonal antibody therapy-associated neurological disorders. Nat. Rev. Neurol. 2011, 7, 165-172. [CrossRef] [PubMed]

21. Mejico, L.J. Infliximab-associated retrobulbar optic neuritis. Arch. Ophthalmol. 2004, 122, 793-794. [CrossRef] [PubMed]

22. Strong, B.Y.; Erny, B.C.; Herzenberg, H.; Razzeca, K.J. Retrobulbar optic neuritis associated with infliximab in a patient with Crohn disease. Ann. Intern. Med. 2004, 140, W34. [CrossRef] [PubMed]

23. Felekis, T.; Katsanos, K.; Christodoulou, D.; Asproudis, I.; Tsianos, E.V. Reversible bilateral optic neuritis after Infliximab discontinuation in a patient with Crohn's disease. J. Crohn Colitis 2009, 3, 212-214. [CrossRef] [PubMed]

24. Ouakaa-Kchaou, A.; Gargouri, D.; Trojet, S.; Hefaiedh, R.; Elloumi, H.; Kochlef, A.; Kilani, A.; Romani, M.; Kharrat, J.; Ghorbel, A. Retrobulbar optic neuritis associated with infliximab in a patient with Crohn's disease. J. Crohn Colitis 2009, 3, 131-133. [CrossRef]

25. Katsanos, A.; Asproudis, I.; Katsanos, K.H.; Dastiridou, A.I.; Aspiotis, M.; Tsianos, E.V. Orbital and optic nerve complications of inflammatory bowel disease. J. Crohn Colitis 2013, 7, 683-693. [CrossRef]

26. Petrelli, E.A.; McKinley, M.; Troncale, F.J. Ocular manifestations of inflammatory bowel disease. Ann. Ophthalmol. 1982, 14, 356-360. [PubMed]

27. Veloso, F.T.; Carvalho, J.; Magro, F. Immune-related systemic manifestations of inflammatory bowel disease. A prospective study of 792 patients. J. Clin. Gastroenterol. 1996, 23, 29-34. [CrossRef] [PubMed] 
28. Lanna, C.C.; Ferrari Mde, L.; Rocha, S.L.; Nascimento, E.; de Carvalho, M.A.; da Cunha, A.S. A cross-sectional study of 130 Brazilian patients with Crohn's disease and ulcerative colitis: Analysis of articular and ophthalmologic manifestations. Clin. Rheumatol. 2008, 27, 503-509. [CrossRef] [PubMed]

29. Chung, J.H.; Van Stavern, G.P.; Frohman, L.P.; Turbin, R.E. Adalimumab-associated optic neuritis. J. Neurol. Sci. 2006, 244, 133-136. [CrossRef] [PubMed]

30. Clemmensen, K.; Akrawi, N.; Stawowy, M. Irreversible optic neuritis after infliximab treatment in a patient with ulcerative colitis. Scand. J. Gastroenterol. 2015, 50, 1508-1511. [CrossRef]

31. Multiple sclerosis risk after optic neuritis: Final optic neuritis treatment trial follow-up. Arch. Neurol. 2008, 65, 727-732. [CrossRef]

32. Sedwick, L.A.; Klingele, T.G.; Burde, R.M.; Behrens, M.M. Optic neuritis in inflammatory bowel disease. J. Clin. Neuro-Ophthalmol. 1984, 4, 3-6.

33. Kochar, B.; Barnes, E.L.; Herfarth, H.H.; Martin, C.F.; Ananthakrishnan, A.N.; McGovern, D.; Long, M.; Sandler, R.S. Asians have more perianal Crohn disease and ocular manifestations compared with white Americans. Inflamm. Intest. Dis. 2018, 2, 147-153. [CrossRef] [PubMed]

34. Afzali, A.; Cross, R.K. Racial and Ethnic Minorities with Inflammatory Bowel Disease in the United States: A Systematic Review of Disease Characteristics and Differences. Inflamm. Bowel Dis. 2016, 22, 2023-2040. [CrossRef] [PubMed]

35. Alexandre, B.; Vandermeeren, Y.; Dewit, O.; Moreels, T.; de Boer, N.; Dhar, A.; Ziady, C.; Shitrit, A.B.; Steinwurz, F.; Jojic, N.; et al. Optic Neuritis Associated or Not with TNF Antagonists in Patients with Inflammatory Bowel Disease. J. Crohn Colitis 2016, 10, 541-548. [CrossRef] 